\title{
Correction to: Optimization Design of Configuration and Layout for Queqiao Relay Satellite
}

\author{
Yong-xin $\mathrm{Gao}^{1} \cdot$ Yi-min $\mathrm{Ge}^{1} \cdot$ Ling-xi $\mathrm{Ma}^{1} \cdot$ Yong-qiang $\mathrm{Hu}^{1} \cdot$ Yin-xin Chen ${ }^{1}$
}

Published online: 3 April 2020

(c) Chinese Society of Astronautics 2020

\section{Correction to:}

Advances in Astronautics Science and Technology https://doi.org/10.1007/s42423-019-00034-0

The publication of this original article unfortunately contained several mistakes.

1. The Article Type "REVIEW" should be changed to "ORIGINAL PAPER".

2. The relay satellite in Fig. 1 is not correct. Figure 1 should be replaced by the following:

3. In section "2.3 Payload", the second paragraph is not correct. The correct sentence should be: Queqiao carries a deploy-able $4.2 \mathrm{~m}$ dish antenna for direct communication with the Earth as a main payload.
4. In section "3.3 Satellite Layout Design", "This satellite carries a laser corner cube retro-reflector (CCR), which has been developed by Huazhong University of Science and Technology (HUST)"is not correct. The correct sentence should be:"This satellite carries a laser corner cube ret-ro-reflector (CCR), which has been developed by Sun Yat-sen University."

We apologize for any inconvenience caused to the readers by these changes.

The original article can be found online at https://doi.org/10.1007/s42 423-019-00034-0.

Yong-xin Gao

gyxstar@163.com

1 DFH Satellite Co., Ltd., Beijing 100094, China 
Fig. 1 Chang'e 4 mission

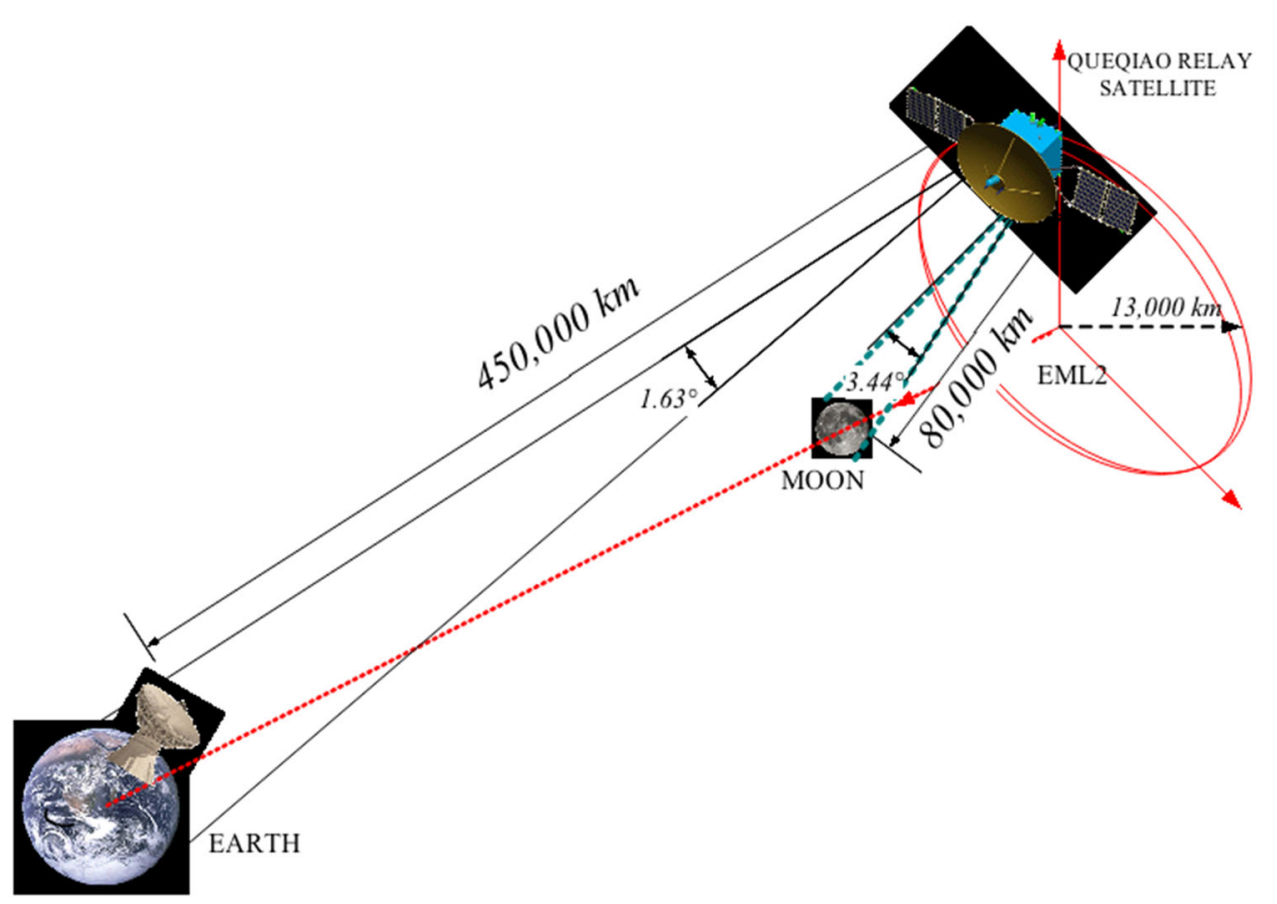

